\title{
Incremental effects of feeding a rumen-inert MUFA supplement to dairy cows on milk trans fatty acid isomer composition
}

\author{
K. E. Kliem ${ }^{1}$, C. K. Reynolds ${ }^{1}$, R. Kirkland ${ }^{2}$, D. J. Humphries ${ }^{1}$, C. E. Barratt ${ }^{1}$ and D. I. Givens ${ }^{1}$ \\ ${ }^{1}$ Animal Science Research Group, School of Agriculture, Policy and Development, University of Reading, Earley Gate, \\ Reading, UK and ${ }^{2}$ Volac International Ltd., Royston, Hertfordshire, UK
}

Milk and dairy products contribute to about $20 \%$ of the average daily intake of trans-fatty acids (TFA) in UK adults ${ }^{(1)}$. The evidence of their effects on human subjects health are equivocal, but at current intakes and food compositional levels TFA from ruminant products are thought not to be a significant risk factor for CVD. However, there is concern that current strategies to reduce milk SFA will lead to substantial increases in TFA concentrations. Feeding rumen-protected sources of cis-MUFA to dairy cows would minimise the appearance of TFA in milk fat, but research to date has been inconsistent ${ }^{(2)}$. The aim of the present study was to measure the effect of feeding incremental amounts of a novel calcium salt (CS) of cis-MUFA on TFA isomer composition of milk fat.

Four multiparous, late-lactation Holstein-Friesian cows were randomly allocated to one of four dietary treatments in a $4 \times 4$ Latin Square design with $21 \mathrm{~d}$ experimental periods. Treatments were a control diet (control) containing no supplemental fat, or the same basal diet with CS of cis-MUFA (Volac International Ltd.) fed at 20, 40 and $60 \mathrm{~g} / \mathrm{kg} \mathrm{DM}$ (CS2, CS4 and CS6, respectively). Milk composition was analysed during the last $3 \mathrm{~d}$ of each experimental period ${ }^{(3)}$.

\begin{tabular}{|c|c|c|c|c|c|c|}
\hline & \multicolumn{4}{|c|}{ Least square means (g/100 g fatty acids) } & \multirow[b]{2}{*}{ SEM } & \multirow[b]{2}{*}{$P($ LIN $)$} \\
\hline & Control & CS2 & CS4 & CS6 & & \\
\hline$\Sigma$ SFA & 71.0 & 63.1 & 57.1 & 51.6 & 1.66 & $<0.001$ \\
\hline$\Sigma$ cis-MUFA & 19.9 & 24.4 & 27.7 & 30.8 & 0.91 & $<0.001$ \\
\hline$\Sigma$ trans-MUFA & 4.7 & 7.4 & 9.6 & 11.7 & 0.80 & $<0.001$ \\
\hline trans-6-8 18:1 & 0.23 & 0.52 & 1.01 & 1.33 & 0.078 & $<0.001$ \\
\hline trans-9 18:1 & 0.22 & 0.52 & 0.78 & 0.96 & 0.060 & $<0.001$ \\
\hline trans-10 18: 1 & 0.37 & 0.76 & 0.89 & 1.10 & 0.075 & $<0.001$ \\
\hline trans-11 18:1 & 1.3 & 2.4 & 3.4 & 4.4 & 0.45 & $<0.001$ \\
\hline trans-12 18: 1 & 0.44 & 0.74 & 1.03 & 1.26 & 0.082 & $<0.001$ \\
\hline trans-13-14 18:1 & 1.2 & 1.2 & 1.5 & 1.6 & 0.071 & 0.006 \\
\hline$\Sigma$ trans-PUFA & 1.9 & 2.9 & 3.6 & 4.3 & 0.26 & $<0.001$ \\
\hline$\Sigma$ CLA & 0.69 & 1.21 & 1.62 & 1.90 & 0.135 & $<0.001$ \\
\hline$\Sigma$ trans-fatty acids & 6.5 & 10.0 & 13.3 & 16.2 & 1.02 & $<0.001$ \\
\hline
\end{tabular}

$P$ (LIN) represents linear effect. CS2, CS4 and CS6 - treatment diets containing 20, 40 or $60 \mathrm{~g} / \mathrm{kg}$ DM calcium salts.

Incremental inclusion of CS linearly $(P<0.001)$ decreased milk fat SFA and increased cis-MUFA concentrations. However, there were also significant increases $(P<0.001)$ in all trans-18:1 isomers measured, some trans-PUFA, and total conjugated linoleic acid (CLA), leading to an overall increase in total TFA $(16 \mathrm{~g} / 100 \mathrm{~g}$ fatty acids for CS6). This indicates CS of cis-MUFA were at least partially metabolised in the rumen and that alternative rumen-protection methods for MUFA are needed to minimise increases in TFA concentrations that accompanied decreased SFA in milk fat.

This research was supported by BBSRC DRINC project BB/1006087/1, and Volac International Ltd., Royston, UK.

1. Henderson L, Gregory J, Irving K et al. (2003) NDNS vol. 2, London: The Stationery Office.

2. Chouinard PY, Girard V \& Brisson GJ (1998) J Dairy Sci 81, 471-481.

3. Givens DI, Kliem KE, Humphries DJ et al. (2009) Animal 3, 1067-1074. 